\title{
Engineering Requirements for Social Sustainability
}

\author{
Maryam Al Hinai \\ Department of Computer Science \\ University of Leicester \\ Leicester, UK \\ Email: masah1@le.ac.uk
}

\author{
Ruzanna Chitchyan \\ Department of Computer Science \\ University of Leicester \\ Leicester, UK \\ Email: rc256@le.ac.uk
}

\begin{abstract}
Software is no longer a passive tool, but is an active agent in shaping modern communities. Yet, to date, software engineers do not endeavour to explicitly state requirements which a software system must fulfil if it is to positively contribute to the well-being (that is the social sustainability) of its user community. This paper presents a proposal on how to bridge this gap. It notes that social sustainability requirements stem from key societal values, such as equity, security, education, which can be elicited into value patterns. Such patterns can then serve as templates for software requirements specification. The viability of this proposal is demonstrated through formation of equity value patterns, which are instantiated as requirements to 6 sample studies. We observe that while each organisation and sub-community will have own diverse cultural and traditional values with respective requirements, the fundamental notions (such as equity, security, freedom) that serve as the core of social sustainability remain relatively stable. It is such values that we propose to elicit into patterns for requirements specification.
\end{abstract}

Index Terms - social sustainability, requirements engineering, value-based design, value patterns

\section{INTRODUCTION}

Social sustainability is often defined as ability of a society to maintain its "social capital" which creates the "basic framework for society", including "cohesion of community for mutual benefit, connectedness between groups of people,... standards of ...ethics..., rules, laws, and information..." [38]. It lowers the cost of working together and facilitates cooperation, e.g., trust lowers transaction costs [38]. Because the functionality, constraints, and properties of a software system are set through Requirements Engineering (RE), RE is also the key stage for engineering sustainability into software [16]. Sustainable software is described as "software whose direct and indirect negative impacts on economy, society, human beings, and the environment resulting from development, deployment, and usage of the software is minimal and/or [such software] has a positive effect on sustainable development" [30].

Nevertheless, requirements engineers have not yet incorporated social sustainability requirements ${ }^{1}$ into software systems engineering [25]. One of the reasons for this is that requirements engineers do not have clear guidelines on what is "positive impact on communities", and how it can be identified, modeled, or measured [25] (except when the functionality of the software is aimed explicitly at supporting

\footnotetext{
${ }^{1}$ As shown in Table III, any type of requirements - irrespective of being functional or non functional, can affect social sustainability, i.e., be a social sustainability requirement.
}

the disadvantaged users, e.g., speech synthesizing software to support those with severe speech impediments [6]).

Yet, the problem of software impact on its user communities has been faced, primarily within the organisational context, for a long time [32] [58] [57] [49] [39] and has, to some degree, been addressed via such techniques as value-based design [36] [29] [42], participatory design [23] [54] [60], user experience evaluation [44] [75] [22], and even iterative agile development [65]. Essentially, all these techniques allow for explicit [29] or implicit [65] [23] incorporation of user values into the intended software systems. In this paper we maintain that the positive contribution of software systems to "user communities" (i.e., its positive contribution to organisational and social structure) manifests when the given software system supports and promotes the social values of the given user community.

However, all of the previously noted techniques [36] [29] [42] [23] [54] [60] [44] [75] [22] [65] set out to discover "from scratch" the values and their respective requirements that would improve the software acceptance in a community or organisation, or would increase user satisfaction with it. While we agree that each organisation and sub-community will have own diverse cultural and traditional values with respective requirements, we also note that there are certain central values (such as equality, security, freedom) that are recognised as fundamental to modern societal well-being. These remain relatively stable, though may have distinctive flavour in various types of communities (e.g., gender equality in western society vs. eastern one). Such values are often universally recognised (e.g., Human Rights convention [1] [4]) and even standardised (e.g., International Standard on Social Accountability [12]). In this paper we propose that such fundamental values should become the starting point of engineering social sustainability requirements for software.

The key contributions of this paper are in:

- Presenting a generic requirements identification methodology that is based on core societal values and, thus, is clearly directed toward social sustainability objective. This methodology is abstract and can be instantiated to support social sustainability requirements in various domains.

- Demonstrating an instantiation of this methodology to support the equality-related requirements. The instantiated methodology is applied to six studies of previously 
written requirements to observe the relevant functional and non-functional social sustainability requirements.

The rest of the paper is organized as follows: in section II we describe the background research on which our work is built, in sections III and IV we demonstrate the suggested methodology and its application respectively. In section $\mathrm{V}$, we present the discussion and related work is summarized in section VI. Finally, section VII concludes the paper.

\section{BACKGROUND}

Since the notion of social sustainability does not directly pertain to software functionality, in Requirements Engineering (RE) it (along with other sustainability dimensions) has been categorised [67] as a soft-goal [27]. Our work is inspired by the NFR catalog [27] that helped to de-mystify the notion of such soft-goals as security, resilience, and usability in RE, and provided clear templates and guidelines on deriving (both functional and non-functional) requirements from these softgoals. While other research has used goal-based techniques for sustainability modeling, we consider two previous efforts particularly relevant to this work. The first one is work by Cabot et. al [21] who modeled environmental sustainability with $I^{*}$ to support decision making for business activity selection. Unlike other researchers that used goal modeling for sustainability, Cabot and colleagues, in spirit of [27], aimed to reveal the generic environmental sustainability goals (i.e., reduce, reuse, recycle) instead of immediately focusing on the project domain specific goals. In the same spirit, we look for the patterns that relate to the key concerns of social sustainability, without immediate focus on specific software project or domain.

The second work is that by Penzenstadler and Femmer [64] [11] who introduce the notion of values into the goal-model for sustainability. Here the goal of sustainability is represented with its five dimensions (i.e., economic, technical, environmental, individual and social). Each dimension is contributed to through a set of values, where a value is a rationale of a natural or moral good. Each value is approximated through a (set of) indicator(s), i.e., qualitative or a quantitative metrics to measure the value. Actions that support achieving the given values (termed activities) are also defined. Optionally, regulations too can affect values. The meta-model presented in this work (see Figure 1) inspired our effort of expressing the social sustainability patterns in terms of values, as well as looking at indicators that approximate societal values.

Furthermore, since our work is concerned with value patterns, it is also closely related to work on value sensitive design (VSD). VSD approaches work on designing technology products with human value consideration [36]. This is done using such techniques as value stories [28], value dams and flows [56] or value scenarios [62]. Yet, the key difficulty faced by the VSD techniques is in the challenge of translating the values into software requirements [42] [41]. We tackle this challenge through extracting requirements templates from our value patterns.

Thus, this paper aims to:

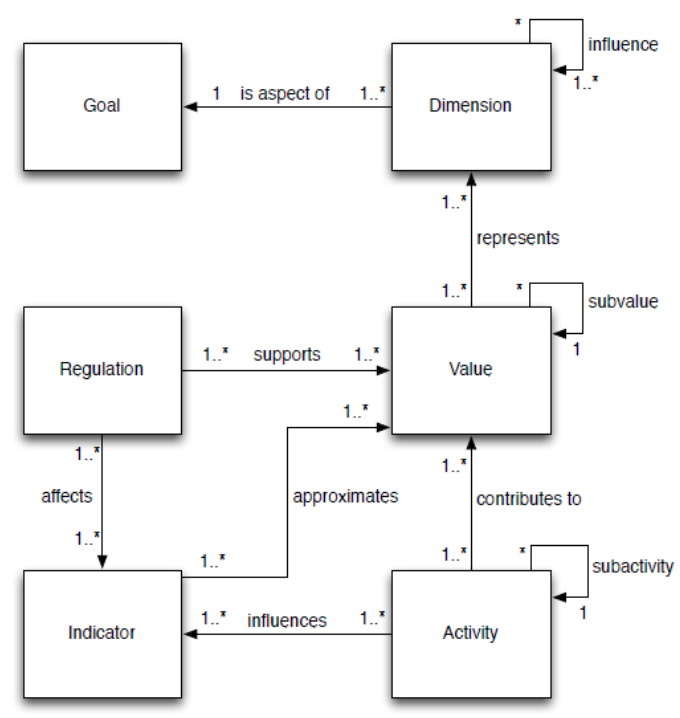

Fig. 1. Meta model of generic sustainability model. Source [64], [11]

- present a methodology for building up value patterns for social sustainability that serve as templates to software requirements, in the same way as NFR catalogs serve as templates for soft-goals;

- demonstrate the use of this methodology for a specific example, for which the case of the equality concern is used in this paper;

- present (an initial set of) templates that concretise the social sustainability concern with specific requirements, with the hope of initiating the start of a fuller reusable requirements catalog on this topic.

Further review of previous, closely related work (such as VSD [42], [36], equality, and sustainability assessment [33], [55], [40]) is presented in section V.

\section{Methodology}

To realize our objective of building a catalog of social sustainability value patterns with their respective requirements templates, we must:

1) first collect the core values that are considered relevant to the notion of social sustainability;

2) for each core value we must elicit value patterns describing it;

3) for each value pattern we must define a template that can be used to specify requirements which integrate the relevant value patterns into software requirements specification.

\section{A. Initial Set of Core Values}

To collect the initial set of core values of social sustainability, we conducted a literature review looking at indicators and metrics considered relevant to social sustainability [13]. Using the sustainability model suggested in [64], [11], we take that these indicators approximate values, our survey provided a detailed perspective on the social values reported upon in the 
academic literature (as per our reviewed sample). While we still continue with the additional paper reviews, we consider this task relatively well addressed, as our additional reviews do not tend to substantially change the notion already reported in [13], and summarized in Table I. Thus, we consider the set of values to be relatively saturated, though we do not claim, in any way, that these are complete.

\section{B. Value Patterns}

To extract value patterns, each of the values presented in Table I has to be addressed individually. In this paper we discuss the derivation of value patterns for the Equality value, though a similar process can be applied to any other entry in Table I. Since, we aim to observe the "regularly repeated arrangement" [31] of the values (which, as further discussed in section $\mathrm{V}$, apply to various domains and are commonly accepted) we refer to these as value patterns.

To analyse the equality value in more detail, we turned to the set of papers from our general review [13] that have addressed equality [52] [45] [19] [24] [74] [76] [59] [47] [48] [17] [68]. We conducted a qualitative text analysis [46], of these papers, whereby a set of codes was defined to categorise concerns related to equality. These codes were then reviewed and refined (e.g., by removing repetition through merging, structuring related topics under common headings, and where necessary, subcategorising topics into further sub-topics). To ensure consistency and objectivity of the process, the 4-eyes principle of qualitative analysis was maintained, whereby the initial coding was performed by the lead author of this paper and reviewed by the second author.

Upon completion of this analysis, three main code categories emerged for equality, each overarching a set of indicators that describe a specific aspect of equality value. These categories are related to stakeholder variability, fairness, and access to services as detailed in Table II.

Here stakeholder variability is focused on identification of factors that can differentiate stakeholders, e.g., according to their age, gender, literacy, etc. Fairness is concerned with fair selection of stakeholder goals to be implemented in the system, e.g., goals of stakeholders who have weaker influence may have large impact on social sustainability and so must be given thorough and fair consideration. Equality for access to services is concerned with providing adequate services to all (diverse) types of stakeholders to enable them equal opportunities to complete a given goal. For example, if a goal is to obtain information from a system, a visually impaired user should be able to use a software system same as a nonimpaired user. In this case, large text fonts and customisable colour schemes or voice-based interfaces may be required.

We further observe that, to support equality, the fairness and access to services categories must be considered with respect to the stakeholder variability sub-categories. For instance, to ensure fair salary, it must be fair with respect to gender variability, educational attainment, economic participation etc. The overview of this value pattern is presented in Figure 2.

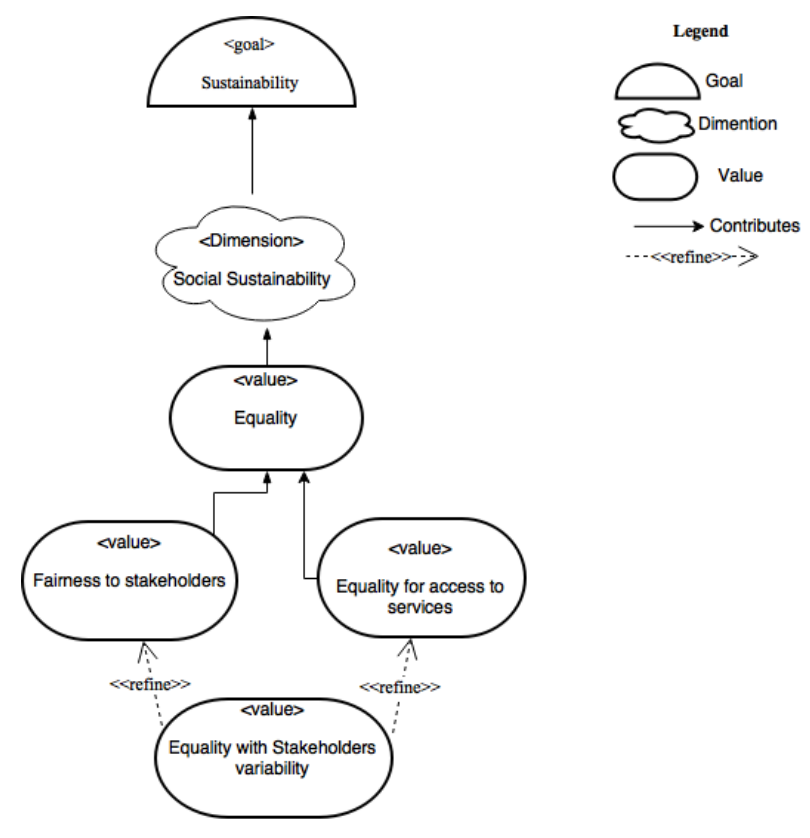

Fig. 2. Equality value pattern

\section{Requirements Templates}

To define a requirements template, we use a set of questions that help us explore as to how a given value can be supported in software requirements. These questions are asked so as to operationalise the defined values and guide requirements elicitation. For the equality with stakeholder variability value, the key questions to consider are:

- Who are the stakeholders?

- What are the differences among stakeholders?

These questions are fundamental, as per the value dependency (depicted in Figure 2) stakeholder variability will have a definitive influence on refinement of other equality values. While the stakeholder identification is a standard task in RE practice, the variability identification is much less clearly demarcated. Thus, for each given stakeholder, the response to the variability elicitation questions can be completed via this simple pattern : "[Stakeholder] has a [difference/variability of...]".

For the fairness value, the questions to be asked are:

- What are the stakeholders' goals for using the software?

- What are the goals of stakeholders (directly or indirectly) affected by use of software?

The wider positive and negative effect of software has to be considered against allowing stakeholders to accomplish their desired goals through the software. However, stakeholders' goals are to be bounded by the scope of the software application.

As social sustainability is about creating and maintaining good conditions in the community now and in the long run, 
TABLE I

VALUES, INDICATORS AND DESCRIPTIONS

\begin{tabular}{|l|l|}
\hline Value & Indicators and Description \\
\hline Employment & Looks into employment opportunities crated and job conditions. Example indicator Number of Full-time/Part-time Workers. \\
\hline Health & $\begin{array}{l}\text { Looks into health conditions impacts as well as health } \\
\text { services provided to people, such as health benefits to workers. }\end{array}$ \\
\hline Equity & $\begin{array}{l}\text { Looks into treating people well regardless of their } \\
\text { differences, for example, wage equality regardless of gender. }\end{array}$ \\
\hline Education & $\begin{array}{l}\text { Looks into the availability of education opportunities } \\
\text { and improvements in the sector, for example, number of students per teacher. }\end{array}$ \\
\hline Security & $\begin{array}{l}\text { Looks into crimes in society and possible way to reduce crimes. } \\
\text { Property crime is an example of indicators used. }\end{array}$ \\
\hline Social cohesion & $\begin{array}{l}\text { Looks into social ties and networks in the community. } \\
\text { Indicators can be related to participation in community activities, such as voluntary work and decision making. }\end{array}$ \\
\hline Services and facilities & $\begin{array}{l}\text { Focuses on available services and facilities in communities, } \\
\text { such as health centers, schools, child care and sports facilities. }\end{array}$ \\
\hline Resilience & Looks into communities' ability to change after a disaster or conflict. \\
\hline Human rights & $\begin{array}{l}\text { Looks into preserving human rights against } \\
\text { violation. Human rights can be related, for example, to discrimination, child labor and forced labor. }\end{array}$ \\
\hline Social acceptance of technology & $\begin{array}{l}\text { Focuses on peoples readiness to accept new } \\
\text { technology or project. This can be observed through knowledge, perception and fear indicators. }\end{array}$ \\
\hline Cultural & $\begin{array}{l}\text { Looks into preservation of cultural values and heritage. } \\
\text { An example indicator can be the level of preserving customary right of indigenous people. }\end{array}$ \\
\hline Political & \begin{tabular}{l} 
Focuses on the level of respect to governmental and organisational laws as well as the trust in those laws. \\
\hline
\end{tabular} \\
\hline
\end{tabular}

TABLE II

VALUES AND INDICATORS IN VALUE PATTERN

\begin{tabular}{|l|l|}
\hline Value Category & Indicators \\
\hline Equality with stakeholder variability & Gender equality (for male, female, transgender variability) \\
& $\begin{array}{l}\text { Educational attainment (for well educated, } \\
\text { educated to literacy level, and illiterate /uneducated types of variability) }\end{array}$ \\
\hline & Political power can affect the way people are treated \\
\hline & Health variability (disable, ill) \\
\hline Fairness & Economic power (high income, low income, employed, unemployed) \\
\hline Employee social fairness & Equal opportunities \\
\hline & Fair salary \\
\hline Fair Competition & Fair competition \\
\hline Equality between residents & Income equality \\
\hline & Equal distribution of resources \\
\hline & Equal ownership of resources \\
\hline Equality with services and facilities & Access to services, facilities, and opportunities \\
\hline
\end{tabular}

it is important to look at the social effects of software as systemic effects, and not be restricted only to immediate usage effects. Thus, we must consider both the full set of weak and strong stakeholders (direct, indirect, intentional and unintentional use), the long term use of software (as many issues only surface upon sufficiently frequent use), as well as the widespread use of software (as some issues only arise when user numbers are substantial) [62] [61], [35]. We aim to consider all such issues to help us in identifying additional (in this case, equality) value-based requirements.

For the equality with services and facilities, the question to be asked is:

- What are the system's functions/ services/ resources needed for the stakeholders to achieve their goal(s)?

For this, the requirements can be presented through a template stating: "[Stakeholder] should get [services] to accomplish [goal]".

Our main objective for using the value patterns and templates driven from them, is to move social sustainability from the abstract soft-goal notion, which is unfamiliar to the requirements engineering practitioner, to a set of patterns that are centered around the (stable) societal values and can be instantiated as a concrete requirements for any given application.

\section{Examples Of the Method Application}

To illustrate the application of the above discussed patterns, we use the example of the Health Watcher (HW) software system [69]. HW is provided by the local government to support citizens in reporting health related concerns (e.g., due to poor food in restaurants, etc.), as well as a tool for providing health-reflated information (e.g., epidemics) to the population. The system has a set of requirements comprised of 9 use cases and 8 NFR specifications. We review this specification, as detailed in Table III

Stakeholder Variability: The list of relevant stakeholders (as per Stakeholder column in Table III) provided in the original use cases is limited to citizens, staff, and client 
TABLE III

Stakeholders, VARiability, GoALs, AND SERVICES

\begin{tabular}{|c|c|c|c|c|}
\hline Stakeholder & Variability & $\begin{array}{l}\text { New/ } \\
\text { Existing }\end{array}$ & Goals/Interest & Services \\
\hline Citizen: & \multirow[t]{2}{*}{$\begin{array}{l}\text { age, } \\
\text { gender, } \\
\text { religion, } \\
\text { language, } \\
\text { physical (dis-) } \\
\text { ability, } \\
\text { technology } \\
\text { use (desktop, } \\
\text { tablets, } \\
\text { mobile, } \\
\text { kiosks), } \\
\text { different } \\
\text { operating } \\
\text { systems } \\
\text { (Android, } \\
\text { iOS, Mac, } \\
\text { Windows) }\end{array}$} & Existing & $\begin{array}{l}\text { Citizens access the system to specify health related complaints as } \\
\text { well as to query the information related to health units and diseases. } \\
\text { The goals are: } \\
\text { - File complaint } \\
\text { - Review Health advice } \\
\text { - Improve Health knowledge } \\
\text { - Follow up complaint status } \\
\text { - Obtain market knowledge } \\
\text { - Preserve own privacy } \\
\text { - Request religious verification (e.g., on kosher food) [variability- } \\
\text { based] } \\
\text { - Use multi-lingual communication [variability-based] } \\
\text { - Support disabled users [variability-based] }\end{array}$ & $\begin{array}{l}\text { Submit and retrieve } \\
\text { complaint details; } \\
\text { Submit/retrieve } \\
\text { health enquiry; } \\
\text { View health } \\
\text { information; } \\
\text { View organisational } \\
\text { record and ranking; } \\
\text { Preserve privacy; } \\
\text { Customise } \\
\text { language; } \\
\text { Provide voice-based } \\
\text { and brail interface }\end{array}$ \\
\hline Staff & & Existing & $\begin{array}{l}\text { System is administered or managed by staff. There are three sub } \\
\text { categories for this stakeholder: Health-Watcher Manager; Attendants; } \\
\text { Inspectors whose main goals are to: } \\
\text { - Forward complaints } \\
\text { - Provide health advice } \\
\text { - Follow up/inspect complaint } \\
\text { - Use multi-lingual communication [variability-based] } \\
\text { - Support disabled users } \\
\text { - Support disabled users [variability-based] }\end{array}$ & $\begin{array}{l}\text { View/update } \\
\text { complaints; } \\
\text { View/Reply to } \\
\text { enquires; } \\
\text { Get alerts on } \\
\text { complaints with no } \\
\text { decision/action; } \\
\text { Customise language } \\
\text { settings; } \\
\text { Customise font size; } \\
\text { Provide voice-based } \\
\text { and brail interface }\end{array}$ \\
\hline $\begin{array}{l}\text { Local } \\
\text { Businesses }\end{array}$ & \multirow[t]{8}{*}{$\begin{array}{l}\text { language, } \\
\text { technology } \\
\text { use (desktop, } \\
\text { tablets, } \\
\text { mobile, } \\
\text { kiosks), } \\
\text { different } \\
\text { operating } \\
\text { systems } \\
\text { (Android, } \\
\text { iOS, Mac, } \\
\text { Windows) }\end{array}$} & New & $\begin{array}{l}\text { Business organizations (e.g. local restaurants etc.) require the system } \\
\text { to get complaints related reports. This helps them to improve the } \\
\text { sanitary conditions in their premises, their goals are: } \\
\text { - Preserve good business reputation } \\
\text { - Comply with health standards } \\
\text { - Improve customer relationships } \\
\text { - Improve competitiveness } \\
\text { - Use multi-lingual communication [variability-based] }\end{array}$ & $\begin{array}{l}\text { View complaints; } \\
\text { Comment on } \\
\text { complaint; } \\
\text { View organisational } \\
\text { record and ranking; } \\
\text { Provide history } \\
\text { report; } \\
\text { Customise language } \\
\text { settings }\end{array}$ \\
\hline \begin{tabular}{|l|} 
Client \\
Organization
\end{tabular} & & Existing & $\begin{array}{l}\text { This stakeholder refers to the organization responsible for funding } \\
\text { the Health-Watcher system. }\end{array}$ & $\ldots$ \\
\hline $\begin{array}{l}\text { Local } \\
\text { Government }\end{array}$ & & New & $\begin{array}{l}\text { Local Government will approve the system's compliance with } \\
\text { applicable laws and policies. }\end{array}$ & $\ldots$ \\
\hline $\begin{array}{l}\text { Environmental } \\
\text { Agency }\end{array}$ & & New & $\begin{array}{l}\text { Environmental agencies require from the system the environmental } \\
\text { related reports. The system would help them to retrieve rectified } \\
\text { complaints to take precautionary measures in future and to monitor } \\
\text { air and water quality, sanitation, co } 2 \text { emission, garbage disposal etc. }\end{array}$ & $\ldots$ \\
\hline \begin{tabular}{|l} 
Financial \\
Institution
\end{tabular} & & New & $\begin{array}{l}\text { Financial institutions need the system to retrieve reports related to } \\
\text { affected citizens and businesses. }\end{array}$ & $\ldots$ \\
\hline $\begin{array}{l}\text { Animal } \\
\text { Protection } \\
\text { Agency } \\
\end{array}$ & & New & $\begin{array}{l}\text { These agencies can benefit from the system to get the reports } \\
\text { containing statistics of affected animals and provide quick response } \\
\text { (e.g., in animal rescue). }\end{array}$ & $\ldots$ \\
\hline $\begin{array}{l}\text { Tourism } \\
\text { Department }\end{array}$ & & New & $\begin{array}{l}\text { Tourism agencies have interest in the system to retrieve the } \\
\text { information for some specific area. The number of complaints and } \\
\text { health information will help these departments to promote the } \\
\text { tourism for that area. } \\
\text { Use multi-lingual communication [variability-based] }\end{array}$ & $\ldots$ \\
\hline $\begin{array}{l}\text { Food } \\
\text { Standards } \\
\text { Agency } \\
\quad \ldots\end{array}$ & & New & $\begin{array}{l}\text { These agencies can get benefit from the system to get the report for } \\
\text { food related complaints. This would help them to promote high } \\
\text { standards of food safety. }\end{array}$ & $\ldots$ \\
\hline
\end{tabular}


organisation (shown as existing in New/Existing column in Table III). By considering the full set of stakeholders (e.g., using the stakeholder lists of [14]), we observe that a number of key stakeholders (such as local businesses against whom complaints would be made, tourism operators who provide recommendations to travelers, environmental agencies concerned about the state of the environment, etc.) have been omitted (shown as new in New/Existing column in Table III). Furthermore, by applying the stakeholder variability pattern, we identify a set of variability characteristics from this pattern (such as age, language, technology availability and platform, etc.) as relevant for each type of stakeholders (Variability column in Table III). It is worth noting that the variability pattern is equally relevant for identification of variability in organisations (e.g., type of hardware available in various business and governmental organisations that would use the system).

Stakeholder Gaols and Fairness: The set of goals identified for each type of stakeholders is provided in the Goals/Interests column of the Table III. These are recovered from the use case (which correspond to functionality required by the relevant stakeholders) and non-functional requirement (which correspond to soft-goals, such as Privacy preservation) specifications of the HW documents. Clearly, in a "green field" development project the goals would be elicited not only from (any available) documentation, but also directly from the stakeholders.

As noted in Figure 2, the variability pattern refines the goals of the stakeholders. Here, we must further consider if any of the aspects of variability identified for the HW study require any of the identified goals to be refined or additional goals to be set. Thus, for instance, we note that food complaints could relate not only to health, but also to religious observance (such as kosher or halal food preparation practices). Hence, a new goal on Request religious verification is added for the citizens. Similarly, we observe that the language aspect of variability is relevant to such stakeholders as citizens, tourism agencies, and staff (though official language is Portuguese, the tourists may often wish to communicate in English). Thus, a new requirement to support the multilingual communication is also defined.

Furthermore, as proposed in the above section, the fair selection on which goals to implement as part of the software system, would be negotiated by the stakeholders (e.g., using Win-Win [18], or similar negotiation techniques). For the present system, it will be necessary to balance the interests of the local businesses, governmental organisations, and citizens. For instance, the businesses may wish to suppress the negative publicity due to unfavourable reports against them, while the citizens may wish to have detailed information on which restaurants have poor food safety record; environmental agencies may wish to minimise travel by optimising travel routes for inspectors to verify received reports, while businesses may wish to have their checks done on priority basis to minimise reputational damage, etc. In this paper, we do not provide a specific fair negotiation approach but simply note that the interests of the weak stakeholder groups (citizens in this case) may be overpowered by stronger groups (e.g., local businesses) if their interests are not represented in a balanced way during requirements negotiation process.

Equal Access to Services: Having identified a set of goals, we now apply the access to services pattern, whereby the set of services necessary to support these goals are identified. Thus, to File a complaint, a citizen must be able to submit complaint details (as noted in Services column of Table III), and so on. As per Figure 2, for the equality pattern, the set of services provided for a given goal must be refined in accordance with the variability characteristics relevant to the stakeholders of the given system. Thus, due to the diverse language and physical (dis-)abilities considered, such services as customise language setting and provide voice-based and brail interface are defined. Such services are necessary to ensure that variability aspects will not disadvantage the diverse set of users in achieving the (agreed upon) goals they expect to accomplish through this system.

\section{Discussion}

\section{A. Emerging Requirements Patterns from Additional Studies}

In order to validate our claim that the application of value patterns could lead to identification of requirements patterns, we applied the above discussed method to 5 more sample requirements specifications, which are summarized in Table IV.

These studies belong to a diverse set of domains (as per Domain column in Table IV), and have been previously defined by independent analysts. Yet, when we review the variability, goals, and services necessary to support equality for various stakeholders, we observe that (nearly always) very similar solutions are applicable to all of the studies, as detailed in Table V. Such solutions can then be clustered according to their goals, with respective services, and variabilities, as previously discussed.

\section{B. Contextualising Requirements and Equality Concern}

It is also notable that many of the equality requirements are routinely used in RE practice without explicit recognition that they relate to equality concern. For example, many requirements derived from stakeholder variability are normally related to accessibility (e.g., service availability as text, braille, speech, sound reproduction etc. [6]), compatibility (e.g., hardware/operating system variability) and user interface (e.g., colour scheme customisation). Similarly, gender and religionrelated requirements also are often classified as non-functional requirements [5] [26] that can affect the acceptability of software [5].

While recognition that stakeholder variability requirements belong under the broader umbrella of equality (or other social sustainability topics) will not diminish their relevance to HCI, we hope that it will also provide a fresh perspective on their role and contributions. Thus, for instance, explicit consideration of religious variability in the HW case study 
TABLE IV

OVERVIEW OF USED STUDIES

\begin{tabular}{|c|c|c|}
\hline Study & Overview & Domain \\
\hline Virtual Art Viewer (AV) [2] & $\begin{array}{l}\text { The VirtualArtViewer is a web application that allows people to explore wide range of } \\
\text { paintings and find information about every piece of art. System administrators create, } \\
\text { edit and store digital representations of the paintings and information about these } \\
\text { paintings. Users interested in paintings can use the website to search, view and print } \\
\text { painting they like. }\end{array}$ & Art \\
\hline Travel App (TA) [72] & $\begin{array}{l}\text { The travel application aims at supporting travelers during their journey. In the appli- } \\
\text { cation, travelers act as information agents and share their travel experiences. Such } \\
\text { experience reporting helps other travelers to structure the traveling chaos, connects } \\
\text { travelers, and helps to enhance public services. }\end{array}$ & Travel \\
\hline $\begin{array}{l}\text { Campbell Prediction System (CP) } \\
\text { [8] }\end{array}$ & $\begin{array}{l}\text { This is a training tool and decision support system based on the Campbell Prediction } \\
\text { System methods. The aim is "to compute, project and visualize the potential fire } \\
\text { behaviour, trigger points and alignments-of-forces on the fire-ground." }\end{array}$ & Fire force training \\
\hline Arcade Game Maker (AGM) [7] & $\begin{array}{l}\text { This is a set of single player games. Player can choose between three options: brickles, } \\
\text { bowling and pong. The requirements specification and design of these games aim to } \\
\text { assist with the learning and application of the software product lines method. }\end{array}$ & $\begin{array}{l}\text { Software Engineering } \\
\text { and Games }\end{array}$ \\
\hline $\begin{array}{l}\text { Personal Investment Management } \\
\text { System (PIMS) [9] }\end{array}$ & $\begin{array}{l}\text { PIMS is a single user system to help investors to manage their investments in different } \\
\text { institutions. It is mainly a bookkeeping application. }\end{array}$ & $\begin{array}{l}\text { Investment } \\
\text { management }\end{array}$ \\
\hline
\end{tabular}

TABLE V

EMERGING REQUIREMENTS PATTERNS

\begin{tabular}{|c|c|c|}
\hline Variability & Solutions for equal access to services & Requirements \\
\hline $\begin{array}{l}\text { Technology } r \text { used } \\
\text { (HW, AV, TA, CP, } \\
\text { AGM, PIM.) }\end{array}$ & $\begin{array}{l}\text { Make the system available in different de- } \\
\text { vices (desktop, tablets, mobile, smart TVs, } \\
\text { kiosks), different operating systems (An- } \\
\text { droid, iOS, Mac, Windows) }\end{array}$ & $\begin{array}{l}\text { Users with different devices and different operating systems must have access } \\
\text { to the system by providing compatible versions of the system running on } \\
\text { desktops, tablets, mobiles (AV,TA, PIM), kiosks (HW), smart TVs (AV, AGM), } \\
\text { and suitable for android, iOS, Mac and Windows. }\end{array}$ \\
\hline $\begin{array}{l}\text { Visual Disability } \\
(\mathrm{HW}, \mathrm{AV}, \mathrm{TA})\end{array}$ & $\begin{array}{l}\text { Different formats of information (audio, } \\
\text { video, text) }\end{array}$ & $\begin{array}{l}\text { Users with blindness and visual impairment must be allowed to view informa- } \\
\text { tion in the system by presenting the information in different formats such as } \\
\text { audio, video, larger text, and text in alternative colours. }\end{array}$ \\
\hline $\begin{array}{l}\text { Language (HW, AV, } \\
\text { AGM,TA) }\end{array}$ & Multilingual interface & $\begin{array}{l}\text { Users speaking in different languages must be supported in accessing the in- } \\
\text { formation in the system by providing multilingual website (languages included } \\
\text { can be based on the most used language in the world, in situ environment). }\end{array}$ \\
\hline $\begin{array}{l}\text { Information media } \\
(\mathrm{HW}, \mathrm{TA})\end{array}$ & Speech synthesizer & $\begin{array}{l}\text { Users can record or query info through voice note that will be analyses through } \\
\text { Speech synthesiser. }\end{array}$ \\
\hline $\begin{array}{ll}\text { Technical } & \text { literacy } \\
\text { level (PIM) } & \end{array}$ & Keyboard shortcuts & $\begin{array}{l}\text { Users with good computer expertise should be able to use the system using } \\
\text { keyboard shortcuts functions. }\end{array}$ \\
\hline Age (HW) & Suitable information details for all ages & $\begin{array}{l}\text { Users from different age ranges should be provided with suitable information } \\
\text { details for all ages. }\end{array}$ \\
\hline Gender (HW) & $\begin{array}{l}\text { Suitable information without offending any } \\
\text { gender }\end{array}$ & $\begin{array}{l}\text { Users from different genders should be provided with age-appropriate infor- } \\
\text { mation. }\end{array}$ \\
\hline Religion (HW) & $\begin{array}{l}\text { Acceptable information aligned with reli- } \\
\text { gious considerations }\end{array}$ & $\begin{array}{l}\text { Users from different religions should be provided with acceptable supportive } \\
\text { information (religious food certificate, health and religious observances (e.g., } \\
\text { healthy diet while fasting or lent), advice on medical procedures of religious } \\
\text { significance (e.g., circumcision or blood transfusion). }\end{array}$ \\
\hline
\end{tabular}

drove forth a new functional requirement for a specific type of query, as shown in Table V.

\section{Indicators and Measures for Value Patterns}

As discussed in section III, the categorisation of equality concerns has originally emerged from the qualitative analysisbased coding with consideration of the metrics and indicators of social sustainability. Thus, the proposed equality model and its related requirements have, by construction, also a set of underlying, and potentially valuable, measurements and indicators. Although we do not review this feature of the present approach in this paper, it will be evaluated and discussed in a future work. Furthermore, since the values used to build the equality value patterns also have a substantial commonality with the ISO 26000 [10] and SA8000 [12] principles and subjects (see section VI), we are convinced (as also corroborated by the presented 6 sample studies) that they will be applicable in different software domains.

\section{RELATED WORK}

\section{A. Social Sustainability}

Social sustainability is an essential aspect of sustainability concept that was introduced in 1987 [20]. Since then, several sustainability frameworks have been adapted to assess social sustainability. For instance, the life cycle assessment (LCA) framework [40] has been extended to consider social sustainability concerns [71] [33], [55], [51].

In terms of software engineering and sustainability, Naumann and colleagues [63] proposed a conceptual reference model to support software teams in development and maintenance of sustainable software. The model is built on LCA where possible effects of software are analyzed and guidance is provided for negative effect reduction. 


\section{B. Value sensitive design (VSD)}

Value sensitive design (VSD) is "a theoretically grounded approach to the design of technology that accounts for human values in a principled and comprehensive manner throughout the design process." [36]. According to [28], most the VSD work appears in the Human-Computer Interaction (HCI) area. Indeed, [36], [15], [56], [42], [35], [28], [41], [29], [70] all discuss application of VSD in user interface and systems design.

Values are what people consider beneficial to their welfare [53]. They are important in personal or group lives [56]; their importance goes beyond their economic worth, as it is values that hold communities together [37]. Thus, "if we can design systems that embody the values of a community, we will have gone a long way towards being able to reliably design systems that will be embraced by that community" [37]. Yet, despite the impacts of human values on software success, values are generally underused in the software engineering [15].

One of the main difficulties with practice of VSD approaches is the lack of a clear, systemic and formal way of translating the values to design recommendations [42] [41]. Such translation requires to have different values operationalised in concrete terms and implementated by specifying design features that correspond to the identified values [41]. Indeed, this is where our proposed method provides clear support with the indicator-based value pattern definition and question-led template construction, allowing for value "operationalisation" into requirements.

Another difficulty in using values for design comes from the variety of potentially conflicting value types. Based on social knowledge, values can be classified as moral, conventional or personal [34]. Moral values are related to peoples judgment based on fairness, justice, rights and welfare [34]. Conventional values are related to actions aiming at better social interactions and personal values will be self-centred [34]. Since this variety of value types can be held by variety of stakeholders, conflicts (called value tensions) between values could occur [56], [34], [28]. We acknowledge the presence of such conflicts in the requirements negotiation process. Though at present we do not provide any definitive resolution method but for already developed fair negotiation practices, such as Win-Win [18].

\section{Equality}

Equality is the right for all members in a society to enjoy living and getting access to services and facilities without being discriminated because of their origin, believes, position, or (dis-)abilities [3]. In/equality can be caused by differences and diversity between individuals [43], opportunities available to individuals and/organisations, fairness of the competition processes [45], etc. Yet, it must be noted that equality and fairness are not the same (e.g., equal distribution of milk between toddlers and adults is not fair distribution, as toddlers need much more milk than adults, who can do well without it). Thus, in many cases it is fair distribution (not equality) that should be used as social sustainability indicator [19]. In our work fairness must be ensured during the requirements negotiations, after which equal access to necessary services is supported through differentiated (as per stakeholder variability) services.

To achieve equality, it is suggested to reduce power assigned to the dominant gender [24], [74], tackle the digital divide [50], [66], increase autonomy of stakeholders [73], ensure equal pay[76], and provide equal access to opportunities such as housing, child care, cultural events, infrastructure [52], etc. Even the International Standards Organisation (ISO) has produced a standard on issues of equality [10].

ISO 26000:2010 [10] is an international standard guideline that aims at helping organisations of any type and size to work in a socially responsible manner [10]. This standard's principles cover common equality indicators discussed in methodology such as gender equality in areas of recruitment, training, payment and community safety and health [10]. In addition, underrepresented groups (e.g. women, girls, people with disability, children, indigenous people, elderly, poor, etc.) should be considered and provided fair treatment and opportunities such as to achieve higher positions in an organisation [10]. ISO 26000 also mentions labour practices to "ensure equal opportunities for all workers and not discriminate either directly or indirectly in any labour practice and eliminate any arbitrary or discriminatory dismissal practices" [10]. In addition, organisations should "provide equal pay for work of equal value" [10]. Furthermore, workers should have access to skills and career development opportunities without any discrimination [10]. The guidelines also note that organisations should undertake fair operating practices that include supporting fair competition between value chain members [10]; respecting property rights and, paying fair compensation to the owner of any acquired or used property [10].

Social Accountability Standard 8000 (SA8000: 2014) provides organisations with guidelines on child labour, forced or compulsory labour, health and safety, freedom of association and collective bargaining, discrimination, disciplinary practices, working hours, remuneration and management system [12]. In term of discrimination, the standard suggest that organisation shall not be part of any discrimination activity whether in "hiring, remuneration, access to training, promotion, termination ... any other condition that could give rise to discrimination" [12]. Additionally, organisations are to make sure that workers are not facing discrimination if they are "union members, representatives of workers and any personnel engaged in organising workers" [12]. Furthermore, the organisation should allow workers to meet their needs related to "race, national or social origin, religion, disability, gender, sexual orientation, family responsibilities, union membership, political opinions or any other condition that could give rise to discrimination" [12].

Our work aims to provide a simple methodology for operationalisation of the issues flagged as relevant in these international standards [10], [12] and research. 


\section{CONCLUSION}

In this paper, we have introduced a requirements engineering methodology that focuses on social sustainability values. Using the example of the equality concern, we presented how we can use the values to derive social sustainability requirements for software systems. The proposed, approach was applied to six studies. Our evaluation shows that the proposed approach is suitable for identification of patterns of equality. Thus, we suggest that it will likely be equally suitable for other stable (commonly accepted) values.

We note that the notion of social sustainability is hugely important in the society at large, as evidenced by the previously discussed standards [10], [12] and research. Yet, unfortunately, the software professionals still have very little awareness of these topics [25] and even less practical engagement with them. This is often attributed to the missing methodological support [25] (along with a lack of knowledge, managerial support, etc.). Our work provides a simple direction towards integrating social sustainability concerns into requirements engineering practice, thus serving as an enabler for these concerns to be integrated into the SE practice at large [16].

Some of the key tasks to be carried out for this work in the immediate future relate to application of this methodology to additional social sustainability concerns to further validate it; undertaking collaborative case studies with RE practitioners to help embed the methodology into actual use, iterate it with the commonplace SE processes (e.g., agile development), and last, but not least, investigate how to best support the fair stakeholder goals negotiation for the presented equality concern.

\section{REFERENCES}

[1] European Convention on Human Rights. Technical report, European Court of Human Rights, Strasbourg cedex.

[2] Requirements document for the virtualartviewer.

[3] Understanding equality. Equality Human Rights Commission.

[4] The universal declaration of human rights. Technical report, United Nations, 1948

[5] Volere requirements specification template @ONLINE, 2007.

[6] Web content accessibility guidelines (wcag) 2.0, 2008.

[7] Arcade game maker pedagogical product line, 2009.

[8] Campbell prediction system, 2009.

[9] Personal investment management system, 2009.

[10] Guidance on social responsibility ISO 26000. Technical report, International Organization for Standardization , Switzerland, 2010. http://www.cnis.gov.cn/wzgg/201405/P020140512224950899020.pdf.

[11] A Generic Model for Sustainability . Technical report, Technical University of Munich , November 2012. http://mediatum.ub.tum.de/attfile/1121449/hd2/incoming/2012Nov/561736.pdf.

[12] Social Accountability 8000 International Standard. Technical report, Social Accountability International, New York, June 2014. http://www.cnis.gov.cn/wzgg/201405/P020140512224950899020.pdf.

[13] M. Al Hinai and R. Chitchyan. Social Sustainability Indicators for Software: Initial Review. In B. Penzenstadler, M. Mahaux, and C. Salinesi, editors, Proceedings of the 3rd International Workshop on Requirements Engineering for Sustainable Systems (RE4SuSy'14), pages 21-27, Karlskrona, Sweden, Aug. 2014.

[14] I. F. Alexander and L. Beus-Dukic. Discovering requirements: how to specify products and services. John Wiley \& Sons, 2009.

[15] B. Barn, R. Barn, and F. Raimondi. On the role of value sensitive concerns in software engineering practice. In Proceedings of the 37th International Conference on Software Engineering - Volume 2, ICSE '15, pages 497-500, Piscataway, NJ, USA, 2015. IEEE Press.
[16] C. Becker, S. Betz, R. Chitchyan, L. Duboc, S. M. Easterbrook, B. Penzenstadler, N. Seyff, and C. C. Venters. Requirements: The key to sustainability. IEEE Software, 33(1):56-65, 2016.

[17] R. Bijl. Never waste a good crisis: Towards social sustainable development. Social Indicators Research, 102(1):157-168, 2010.

[18] B. Boehm, P. Grünbacher, and R. O. Briggs. Developing groupware for requirements negotiation: lessons learned. Software, IEEE, 18(3):46-55, 2001.

[19] M. Bos, D. Murray-Rust, D. Merrey, H. Johnson, and W. Snellen. Methodologies for assessing performance of irrigation and drainage management. Irrigation and Drainage Systems, 7(4):231-261, 1994.

[20] G. H. Bruntland. Our Common Future. Technical report, The World Commission on Environment and Development, Oxford, 1987. http://www.un-documents.net/wcedocf.htm.

[21] J. Cabot, S. Easterbrook, J. Horkoff, L. Lessard, S. Liaskos, and J.N. Mazón. Integrating sustainability in decision-making processes: A modelling strategy. In Software Engineering-Companion Volume, 2009. ICSE-Companion 2009. 31st International Conference on, pages 207210. IEEE, 2009

[22] G. Changyuan, W. Shiying, and Z. Chongran. Research on user experience evaluation system of information platform based on web environment. In Measurement, Information and Control (ICMIC), 2013 International Conference on, volume 01, pages 558-562, Aug 2013.

[23] K. Cheong and A. Mitchell. Human-Computer Interaction - INTERACT 2015: 15th IFIP TC 13 International Conference, Bamberg, Germany, September 14-18, 2015, Proceedings, Part III, chapter Kwento: Using a Participatory Approach to Design a Family Storytelling Application for Domestic Helpers, pages 493-500. Springer International Publishing, Cham, 2015.

[24] A. Chib and A. L. E. Komathi. Extending the technology-communitymanagement model to disaster recovery: Assessing vulnerability in rural asia. In Information and Communication Technologies and Development (ICTD), 2009 International Conference on, pages 328-336, April 2009.

[25] R. Chitchyan, C. Becker, S. Betz, L. Duboc, B. Penzenstadler, N. Seyff, and C. C. Venters. Sustainability design in requirements engineering: State of practice. In 38th IEEE/ACM International Conference on Software Engineering, ICSE 2016, Austin, Taxes, May 14-22, 2016, Volume 2, 2016

[26] L. Chung. Non-functional requirements, practices and recommendations @ ONLINE. lecture note.

[27] L. Chung, B. A. Nixon, E. Yu, and J. Mylopoulos. Non-Functional Requirements in Software Engineering. Springer US, Boston, MA, 2000.

[28] C. Detweiler and M. Harbers. Value stories: Putting human values into requirements engineering. In Joint Proceedings of REFSQ-2014 Workshops, Doctoral Symposium, Empirical Track, and Posters, co-located with the 20th International Conference on Requirements Engineering: Foundation for Software Quality (REFSQ 2014), Essen, Germany, April 7-10, 2014., pages 2-11, 2014.

[29] C. Detweiler and K. V. Hindriks. Value-sensitive design patterns for pervasive health care. In Tenth Annual IEEE International Conference on Pervasive Computing and Communications, PerCom 2012, March 19. 23, 2012, Lugano, Switzerland, Workshop Proceedings, pages 908-913, 2012.

[30] M. Dick, S. Naumann, and N. Kuhn. What Kind of Information Society? Governance, Virtuality, Surveillance, Sustainability, Resilience: 9th IFIP TC 9 International Conference, HCC9 2010 and 1st IFIP TC 11 International Conference, CIP 2010, Held as Part of WCC 2010, Brisbane, Australia, September 20-23, 2010. Proceedings, chapter A Model and Selected Instances of Green and Sustainable Software, pages 248-259. Springer Berlin Heidelberg, Berlin, Heidelberg, 2010.

[31] C. Dictionaries. Cambridge dictionaries online, 2016.

[32] E. A. Dykstra and R. P. Carasik. Structure and support in cooperative environments: The amsterdam conversation environment. International journal of man-machine studies, 34(3):419-434, 1991.

[33] T. Ekvall. Nations in social lca. The International Journal of Life Cycle Assessment, 16(1):1-2, 2010.

[34] B. Friedman. Human Values and the Design of Computer Technology. CSLI lecture notes. Cambridge University Press, 1997.

[35] B. Friedman and D. Hendry. The envisioning cards: A toolkit for catalyzing humanistic and technical imaginations. In Proceedings of the SIGCHI Conference on Human Factors in Computing Systems, CHI '12, pages 1145-1148, New York, NY, USA, 2012. ACM. 
[36] B. Friedman, P. Kahn, and A. Borning. Value sensitive design: Theory and methods. University of Washington technical report, pages 02-12, 2002.

[37] J. A. Goguen. Semiotics, compassion and value-centered design. In Virtual, Distributed and Flexible Organisations, pages 3-14. Springer, 2004.

[38] R. Goodland. Sustainability: Human, social, economic and environmental. Encyclopedia of Global Environmental Change, 2002.

[39] J. Grudin and J. Pruitt. Personas, participatory design and product development: An infrastructure for engagement. In $P D C$, pages 144 152, 2002.

[40] J. B. Guinée. Handbook on life cycle assessment: operational guide to the ISO standards, volume 7. Kluwer Academic Publishers, Dordrecht;Boston;, 2002;2004;

[41] M. Harbers, C. Detweiler, and M. A. Neerincx. Embedding stakeholder values in the requirements engineering process. In Requirements Engineering: Foundation for Software Quality - 21st International Working Conference, REFSQ 2015, Essen, Germany, March 23-26, 2015. Proceedings, pages 318-332, 2015.

[42] M. Harbers and M. A. Neerincx. Value sensitive design of automated workload distribution support for traffic control teams. In Engineering Psychology and Cognitive Ergonomics - 11th International Conference, EPCE 2014, Held as Part of HCI International 2014, Heraklion, Crete, Greece, June 22-27, 2014. Proceedings, pages 12-21, 2014.

[43] F. Henwood, S. Wyatt, N. Miller, and P. Senker. Critical perspectives on technologies, in/equalities and the information society, chapter 1, pages 1-18. Routlage London, England, 2000.

[44] C. Hochleitner, W. Hochleitner, C. Graf, and M. Tscheligi. Game User Experience Evaluation, chapter A Heuristic Framework for Evaluating User Experience in Games, pages 187-206. Springer International Publishing, Cham, 2015.

[45] S. A. Hosseinijou, S. Mansour, and M. A. Shirazi. Social life cycle assessment for material selection: a case study of building materials. The International Journal of Life Cycle Assessment, 19(3):620-645, 2013.

[46] H.-F. Hsieh and S. E. Shannon. Three approaches to qualitative content analysis. Qualitative health research, 15(9):1277-1288, 2005.

[47] R. Jitpakdee and G. B. Thapa. Sustainability analysis of ecotourism on yao noi island, thailand. Asia Pacific Journal of Tourism Research, 17(3):301-325, 2012.

[48] K. R. Jones and L. Mucha. Sustainability assessment and reporting for nonprofit organizations: Accountability for the public good. VOLUN TAS: International Journal of Voluntary and Nonprofit Organizations, 25(6):1465-1482, 2014

[49] F. Kensing and J. Blomberg. Participatory design: Issues and concerns. Computer Supported Cooperative Work (CSCW), 7(3-4):167-185, 1998

[50] A. Koehler and C. Som. Effects of pervasive computing on sustainable. IEEE Technology and Society Magazine, 24(1):15-23, Spring 2005.

[51] C. Labuschagne, A. Brent, and S. Claasen. Environmental and social impact considerations for sustainable project life cycle management in the process industry. Corporate Social Responsibility and Environmental Management, 12(1):38-54, 2005. cited By 29.

[52] C. Landorf. Evaluating social sustainability in historic urban environments. International Journal of Heritage Studies, 17(5):463-477, 2011.

[53] E. A. Locke. Theories of cognitive self-regulation the motivation sequence, the motivation hub, and the motivation core. Organizational Behavior and Human Decision Processes, 50(2):288 - 299, 1991.

[54] B. Longo. R u there? cell phones, participatory design, and intercultural dialogue. IEEE Transactions on Professional Communication, 57(3):204-215, 2014

[55] Y. Manik, J. Leahy, and A. Halog. Social life cycle assessment of palm oil biodiesel: a case study in jambi province of indonesia. The International Journal of Life Cycle Assessment, 18(7):1386-1392, 2013.

[56] J. K. Miller, B. Friedman, and G. Jancke. Value tensions in design: the value sensitive design, development, and appropriation of a corporation's groupware system. In Proceedings of the 2007 International ACM SIGGROUP Conference on Supporting Group Work, GROUP 2007, Sanibel Island, Florida, USA, November 4-7, 2007, pages 281-290, 2007.

[57] M. J. Muller and S. Kuhn. Participatory design. Communications of the ACM, 36(6):24-28, 1993.

[58] M. J. Muller, D. M. Wildman, and E. A. White. Taxonomy of participatory design practices: a participatory poster. In Posters and short talks of the 1992 SIGCHI conference on Human factors in computing systems, pages 34-34. ACM, 1992.
[59] K. Murphy. The social pillar of sustainable development: a literature review and framework for policy analysis. Sustainability: Science, Practice, \& Policy, 8(1), 2012.

[60] U. Mushtaq and K. Hall. Power and agency in health information technology: towards a more meaningful participatory design for sustainable development. In Science and Technology for Humanity (TIC-STH), 2009 IEEE Toronto International Conference, pages 1036-1041, Sept 2009.

[61] L. P. Nathan, B. Friedman, P. Klasnja, S. K. Kane, and J. K. Miller. Envisioning systemic effects on persons and society throughout interactive system design. In Proceedings of the 7th ACM conference on Designing interactive systems, pages 1-10. ACM, 2008.

[62] L. P. Nathan, P. V. Klasnja, and B. Friedman. Value scenarios: A technique for envisioning systemic effects of new technologies. In $\mathrm{CHI}$ '07 Extended Abstracts on Human Factors in Computing Systems, CHI EA '07, pages 2585-2590, New York, NY, USA, 2007. ACM.

[63] S. Naumann, M. Dick, E. Kern, and T. Johann. The GREENSOFT Model: A Reference Model for Green and Sustainable Software and Its Engineering. Sustainable Computing: Informatics and Systems, 1(4):294-304, Dec. 2011.

[64] B. Penzenstadler and H. Femmer. A Generic Model for Sustainability with Process- and Product-Specific Instances. In Proceedings of the Workshop on Green in/by Software Engineering (GIBSE'13), pages 38, Fukuoka, Japan, Mar. 2013. ACM.

[65] M. Pikkarainen, O. Salo, R. Kuusela, and P. Abrahamsson. Strengths and barriers behind the successful agile deployment-insights from the three software intensive companies in finland. Empirical Software Engineering, 17(6):675-702, 2011.

[66] J. Rajapakse. Impact of telecentres on sri lankan society. In Computing and Networking Technology (ICCNT), 2012 8th International Conference on, pages 281-286, Aug 2012.

[67] A. Raturi, B. Penzenstadler, B. Tomlinson, and D. J. Richardson. Developing a sustainability non-functional requirements framework. In Proceedings of the 3rd International Workshop on Green and Sustainable Software, GREENS 2014, Hyderabad, India, June 1, 2014, pages $1-8,2014$

[68] D. Sharma and S. Shardendu. Assessing farm-level agricultural sustainability over a 60-year period in rural eastern india. The Environmentalist, 31(3):325-337, 2011.

[69] S. Soares, E. Laureano, and P. Borba. Implementing distribution and persistence aspects with aspectj. In ACM Sigplan Notices, volume 37, pages 174-190. ACM, 2002.

[70] P. C. Tsai, Y. S. Deng, and M. C. Chuang. Proposing a values exchange model: A service design tool for interpretation of values patterns in a wellness context. In Service Science and Innovation (ICSSI), 2013 Fifth International Conference on, pages 155-161, May 2013.

[71] S. Umair, A. Björklund, and E. E. Petersen. Social life cycle inventory and impact assessment of informal recycling of electronic ict waste in pakistan. In Hilty $L$, Aebischer E, Andersson $G$, Lohmann W, Proceedings of the First International Conference on Information and Communication Technologies for Sustainability ETH Zurich, pages 5258, 2013.

[72] T. van Dijk. Requirements specification for the social travel app, 2012.

[73] V. Vasileiadis, A. Moonen, M. Sattin, S. Otto, X. Pons, P. Kudsk, A. Veres, Z. Dorner, R. van der Weide, E. Marraccini, E. Pelzer, F. Angevin, and J. Kiss. Sustainability of european maize-based cropping systems: Economic, environmental and social assessment of current and proposed innovative ipm-based systems. European Journal of Agronomy, 48:1-11, 2013. cited By 7.

[74] P. R. Walsh. Creating a "values" chain for sustainable development in developing nations: where maslow meets porter. Environment, Development and Sustainability, 13(4):789-805, 2011.

[75] L. T. Yong. User experience evaluation methods for mobile devices. In Innovative Computing Technology (INTECH), 2013 Third International Conference on, pages 281-286, Aug 2013.

[76] L. Zhen, S. Cao, Y. Wei, O. Dilly, X. Liu, F. Li, H. Koenig, K. Tscherning, and K. Helming. Comparison of sustainability issues in two sensitive areas of china. Environmental Science and Policy, 12(8):1153 - 1167, 2009. Sustainability impact assessment and land-use policies for sensitive regions. 